\title{
Signaling the Environmental Performance of \\ Polluting Products to Green Consumers
}

\author{
By Philippe Mahenc* \\ LERNA-INRA, \\ University Toulouse I, Manufacture-bât F \\ 21, Allée de Brienne \\ 31000 Toulouse, FRANCE. \\ Email: mahenc@univ-perp.fr
}

June 22, 2006

\begin{abstract}
*LERNA-INRA, University Toulouse I, Manufacture-bât F, 21 Allée de Brienne 31000 Toulouse and GEREM, Dpt de Sciences Economiques, University of Perpignan, 52 avenue de Villeneuve 66860 Perpignan Cedex, France. Email: mahenc@univ-perp.fr. I wish to thank two anonymous referees, Bernard and François Salanié for helpful comments.
\end{abstract}


This article studies the role of pricing as a signal of environmental performance for polluting products to green consumers. It is shown that high environmental performance is signaled through a high price when less polluting products are more costly to produce. Consequently, the level of pollution is distorted downward relative to what would prevail under full information.

Keywords: Environmental Performance, Pollution, Quality, Signaling.

JEL Code: D42, D82, L15,Q50. 


\section{Signaling the Environmental Performance of Polluting Products to Green Consumers}

\section{Introduction}

In recent years, there has been a noticeable increase in the number of products claiming that they are "green", i. e., products that generate less environmental harm, especially in the United States and Europe. Examples given by Cason and Gangadharan (2002) include sustainable forestry, electricity generated from renewable resources, organically grown agricultural products and can be extended to hybrid cars, dolphin-safe tuna, biodegradable washing powders, etc. As pointed by recent papers in the environmental economics literature, many green products are introduced by firms possessing market power such as Unilever, Toyota, Honda or MacDonalds ${ }^{1}$. This is not surprising since environmentally friendly labels, or eco-labels, can be regarded as effective instruments in the hands of firms for differentiating their products from conventionally produced substitutes, hence increasing market power.

Firms infatuation for green claims suggests that they are more and more

\footnotetext{
${ }^{1}$ These examples can be found in Deltas, Khanna and Ramirez (2004). See also Innes and Bial (2002) for the reformulated gasoline ARCO, and Nimon and Beghin (1999) for an applied work producing empirical evidence on the existence of price premiums in the U. S. green apparel market which is dominated by one large firm.
} 
willing to become or, at least, be perceived as environmentally friendly. Nevertheless, there is a suspicion that green claims alone fail to transmit all information about the environmental performance of newly introduced products to consumers. There are a variety of reasons for this.

A first reason is that many new products of an allegedely superior quality passe through an introductory phase, in which consumers can hardly ascertain the quality in question. Since Nelson (1970), this type of products are the so-called "experience goods". Green products that boast about their high environmental quality are also susceptible to asymmetric informational problem in their introductory phase (see Karl and Orwat (1999)). More particularly, when they present multi-dimensional environmental characteristics and/or are introduced rapidly as is now the case ${ }^{2}$, which makes it difficult to thoroughly regulate all environmental claims in advertising and packaging. These claims range from vague statements such as those reviewed by Iyer and Bannerjee $(1993)^{3}$ to more or less simplistic voluntary eco-label schemes ${ }^{4}$ and standards imposed by the guidelines of Trade Commissions such as the Federal Trade Commission in the United States or the Trade Practices Commission in Australia. As observed by Cason and Gangadha-

\footnotetext{
${ }^{2}$ For example, 800 new organic products were introduced in the first half of 2000 in the US, from the organic farming websites of the US Department of Agriculture, "Recent Growth Patterns in the US Organic Foods Market", 2004, Carolyn Dimitri and Catherine Green.

${ }^{3}$ For instance, "Brand $\mathrm{X}$ is environmentally friendly".

${ }^{4}$ See Church (1994) for a criticism.
} 
ran (2002), these guidelines differ in stringency from one state or country to another. The patchwork of standards in the various certification programs is likely to cause informational problem. Even though it is recognized that ecolabeling systems partially convey verifiable information, the assumption that they fail to transmit all information about the environmental performance of products is likely to be met in reality. This paper investigates another natural way for firms to transmit information, namely, price.

A second reason why consumers may lack information on the environmental performance of products is that communication of accurate information is very costly. Investigating and enforcing reasonably truthful environmental claims requires an environmental agency to not only employ regulations and civil enforcement procedures but also impose strong penalties for misrepresentation. The discriminatory contracts which should be used by the regulator as means of providing firms with the correct incentives for fully reporting their information may be hardly acceptable from a legal and political point of view. Furthermore, information on the environmental performance of products provided by private systems may not be verifiable to third parties. If the court finds it hard to determine whether a product or a process is clean or dirty, then consumers must lend few credence to environmental statements made by firms, since they cannot be enforced.

Finally, a third reason why consumers may not be accurately informed about the environmental performance of green products is that they are re- 
moved from the production process. Firms would be expected to have better information regarding the substitution possibility of cleaner technologies than would consumers. The latter usually lack the technical knowledge required for assessing the true environmental costs of inputs or other idiosynchratic characteristics of the production process. Hence, a firm is likely to be more aware than consumers of the least-cost combination of inputs that preserves best the environment.

The purpose of this paper is to study the role of pricing as a signal of environmental performance. For this, a powerful firm is assumed to have private information about the environmental performance of its product. The main result is that high environmental performance is signaled through a high price when marginal production costs increase with environmental performance. The intuition can be set out as follows. When higher environmental performance is more expensive to produce, a clean firm has less to lose than a dirty firm from output reduction. Hence, a clean firm is better off signaling high environmental performance with a high price instead of a low one. A high price means good news for the environment, not only because it fully reveals cleanness, but also because, to prove this cleanness, the firm must shrink emissions below the level that would prevail if environmental performance were perfectly observable to consumers.

In the present model, pollution is taken to be a non excludable bad in consumption and consumers are assumed to be environmentally aware in the 
sense that they are willing to pay more for cleaner products. This is reminiscent of a recent theoretical literature in which environmental friendliness is considered as a vertical attribute of products (Arora and Gangopadhyay ((1995), Cremer and Thisse (1999), Bansal and Gangopadhyay (2003), Boyer, Mahenc and Moreaux (2004)). The willingness to pay for environmental attributes through consumption obey various motives: not only purely private motives such as health care, but also impurely altruistic motives such as the guilt complex from purchasing polluting goods, which is quite similar to what Andreoni (1995) calls a "cold prickle"5. The marketing research has produced various evidence that consumers are willing to pay more for environmental friendly products. For instance, polls reveal some willingness to pay more for products that are biodegradable and have recyclable packaging (see Cairncross (1992) and Cason and Gangadharan (2002)).

The result here that prices signaling high environmental performance are biased upward when it is more expensive to produce is a clear generalization of the familiar result in industrial organization that high prices signal high product quality (Milgrom and Roberts (1986) or Bagwell and Riordan (1991)). This is not surprising since both conclusions crucially hinge on the fairly close assumptions that a cleaner product and a higher-quality product are both more costly to produce. Consequently, the output restriction asso-

\footnotetext{
${ }^{5}$ Such an altruism is said "impure" because, rather than care about the welfare of other people, individuals care about the act of doing bad for other people .
} 
ciated with an increase in price is less damaging to a cleaner product as it is to a higher-quality product. Similarly, the temptation for dirtier producers to mimic cleaner producers parallels the argument in Schmalensee (1978) that a natural way for low-quality producers to pretend that quality is high is to duplicate the prices charged by high-quality producers (see also Tirole (1988), p. 110-111).

The main difference between the present model and those dealing with the signaling of product quality is that consumers' willingness to pay for a product is affected here by the total level of pollution associated with output. Industrial organization usually treats quantity and quality as independent decision variables. In contrast, quantity and environmental quality are necessarily linked through a pollutant emissions function.

The paper is organized in three sections including the present introduction. Section II presents the basic model under complete information. The extension to a signaling model with a continuum of types is analyzed in Section III, which states the existence of separating equilibria. Conclusions are drawn in Section IV.

\section{Basic model under complete information}

Consider a firm which produces an amount $q$ of a good that generates a level $e$ of pollution, either during the production process or through its use. 
The environmental friendliness of the product is measured by the emission function $e \equiv t(q) / \theta$, where $\theta$ is an index for the environmental performance: a higher $\theta$ means a cleaner product $^{6}$. The emission function is taken to be increasing and convex in $q$, that is, $t(0)=0, t^{\prime}(q)>0$ and $t^{\prime \prime}(q) \geq 0$, where primes denote derivatives: the greater the output, the more pollution and, as the pollution emissions increase, larger and larger quantities of good must be given up to achieve unit reductions in pollution. The technological process is described by the cost function $c(q, \theta)$, with $c(0, \theta)=0$, $c_{\theta}(q, \theta)>0, c_{q}(q, \theta)>0$ and $c_{q q}(q, \theta) \geq 0$, where subscripts denote partial derivatives (here and throughout), that is, production costs depend upon the environmental performance of the product, pollution abatement is increasingly costly and marginal production costs are nondecreasing.

Two alternative assumptions are then possible on the relationship between environmental performance and the productivity of the firm: environmental performance either raises or reduces marginal costs, i. e., $c_{q \theta}(q, \theta)>0$ and $c_{q \theta}(q, \theta)<0$, respectively. We will focus on the first notion, which is the most traditional hypothesis in the environmental economics literature (see Palmer, Oates and Portney (1995)). However, it will be pointed out how the results change with the alternative hypothesis promoted by Porter and Van

\footnotetext{
${ }^{6}$ Note that the relation between output and emissions is often assumed to be fixed in the environmental literature (see, for example, Baumol and Oates (1988, p. 222), Kolstad (2000, p. 125), Innes and Bial (2002)), in which case $\theta$ measures the release of pollutants such as $\mathrm{NO}_{x}, \mathrm{CO}, \mathrm{SO}_{2}$, per unit of product.
} 
der Linde (1995) that products of higher environmental quality are cheaper to produce ${ }^{7}$.

Consumers want the good but they don't want to be harmed by pollution. They are assumed to be environmentally aware. They value environmental friendliness as a vertical attribute of the purchased product in the sense that they are willing to pay more for a cleaner product. Pollution is considered to be non-excludable and so everyone consumes it to the same degree. Generally, polluting emissions create both social and private costs. The social cost $V(e)$ is the global environmental damage affecting all individuals whether they consume or not the product. Let $v(e)$ denote the private cost, that is, a personal damage caused by pollution, such as the adverse effects on health of ingesting polluted air and water, eating food containing chemical or exposing the organism to toxic substances. Obviously, the negative utility due to pollution is more than offset against the utility given by the polluting goods to consumers, otherwise they would not buy. Another interpretation for the private cost of pollution is reminiscent of Andreoni (1995): consumers lose intrinsic utility from purchasing a polluting good because they have a coldprickle feeling. Along this line, $v(e)$ represents the guilt from consuming a good that has not been produced in a sustainable manner. It will be assumed here that the social and private costs enter consumer's utility function in a

\footnotetext{
${ }^{7}$ Porter and Van der Linde (1995) present a series of case studies rather than propose a formal model to illustrate this viewpoint.
} 
separable way.

Consumers buy at most one unit of the product at price $p$. They are heterogeneous in their basic willingness to pay for the product but homogeneous in their valuation of the damage caused by pollution. The global environmental damage is the same for buyers and non-buyers, hence will not play any role in the analysis. All buyers lose the same intrinsic utility $v(e)$ from purchasing the polluting product. Thus, a buyer of type $r$ has a willingness to pay $r-v(e)-V(e)$ for one unit of the product, while a non-buyer has utility $-V(e)$. It is assumed that $v(0)=0, v^{\prime}(e)>0$ and $v^{\prime \prime}(e) \geq 0$, that is, consumers are willing to pay a higher price for a product that generates less environmental harm and the marginal damage is increasingly harmful. Writing $v(e)=v(\theta t(q))$, the function $v($.$) can be related to "unfavorable$ atmosphere" functions, as defined by Meade (1952): due to external diseconomies, the utility that a user derives from consumption decreases with the total amount of product. In this section, consumers perfectly know the firm emission function $t(q) / \theta$.

The basic willingness to pay, $r$, is assumed to be uniformly distributed over $[0, R]$, with $R>0$. Letting $\widetilde{r}(p, \theta)$ denote the marginal consumer who is indifferent between buying or not, $\widetilde{r}(p, \theta)$ solves the following equation for $r$ inside $[0, R]$ :

$$
r-v(t(R-r) / \theta)-p=0
$$


From the Implicit Function Theorem, $\widetilde{r}(p, \theta)$ is continuously differentiable and the first-order effect of $p$ is given by:

$$
\widetilde{r}_{p}(p, \theta)=\left(1+v^{\prime}(t(R-r) / \theta) t^{\prime}(R-r) / \theta\right)^{-1}
$$

It can be checked that, under our assumptions, the market area is always strictly lower than $R$, and so boundary problems are avoided ${ }^{8}$. The demand for the product is equal to the number of consumers with basic willingness to pay $r$ such that $r \in[\widetilde{r}(p, \theta), R]$. Normalizing the size of the population of consumers to 1 , this yields a demand function $D(p, \theta) \equiv R-\widetilde{r}(p, \theta)$ and the firm earns profits equal to

$$
\pi(p, \theta) \equiv p D(p, \theta)-c(D(p, \theta), \theta)
$$

Let $\eta(\theta) \equiv-D_{p}(p, \theta) p / D(p, \theta)$ denote the price elasticity of demand and $p^{*}(\theta)$ the profit maximizing price. Further, assume $\eta(\theta)>1, \forall p, \theta$, to ensure the existence of an interior solution.

Lemma 1: The firm charges the price satisfying $\frac{p^{*}(\theta)-c_{q}\left(D\left(p^{*}(\theta), \theta\right), \theta\right)}{p^{*}(\theta)}=$ $\frac{1}{\eta(\theta)}$

Proof : (see Appendix 1)

\footnotetext{
${ }^{8}$ Indeed, $p=-v[t(R / \theta)]$ and $r=0$ solve equation (1). As $\widetilde{r}_{p}(p, \theta)>0, \widetilde{r}(0, \theta)>0$ and $\widetilde{r}(p, \theta)>0$ for all $p$ inside $[0, R]$. The function $\widetilde{r}(p, \theta)$ is monotonically increasing in $p$, reaching the maximum value at $\widetilde{r}(R, \theta)=R$ and so, the market area $R-\widetilde{r}(p, \theta)$ is strictly lower than $R$ for all $p<R$.
} 
Lemma 1 records the standard result that, under complete information, the Lerner index is equal to the inverse of the price elasticity of demand: the firm power is a decreasing function of price elasticity of demand. In the present context, if price elasticity decreases with $\theta$, cleanness is a source of market power since it makes demand less elastic.

\section{A signaling model of environmental perfor-}

\section{mance}

Consider now that the environmental performance of the product is not observable to consumers by assuming that the index $\theta$ is private information of the firm. Environmental performance is assumed to be determined by nature and is thus exogenous to the firm. After observing the price set by the firm,

consumers rely on their inferences $\widehat{\theta}$ about the true index $\theta$ to make their purchase decision. The firm, in turn, must take into account how its choice of price influences consumers' inferences. Employing the concept of sequential equilibrium, we restrict attention to separating equilibria in which clean and dirty firms choose different prices, and so the private information on environmental performance is revealed. The setting and the proof techniques in Mailath (1987) are readily adapted for this purpose.

In any equilibrium, the firm optimally chooses the price $p$, expecting 
consumers to make purchase decisions that maximize their expected utility given their beliefs. By definition, these beliefs leave no uncertainty about the firm environmental performance in a separating equilibrium. Following Mailath (1987), there is no need to specify consumers' prior beliefs for the analysis of separating equilibria. Defining $D(p, \widehat{\theta})$ as the demand function $D(p, \theta)$ where $\theta=\widehat{\theta}$ stands now for consumers' inferences, let $\pi(p, \theta, \widehat{\theta}) \equiv$ $p D(p, \widehat{\theta})-c(D(p, \widehat{\theta}), \theta)$ be the reduced form profit function for a firm of type $\theta$, anticipating the purchase decision of consumers who draw inferences $\widehat{\theta}$ upon seeing $p$. The set of types is assumed to be a compact interval $[\underline{\theta}, \bar{\theta}] \subset \mathbb{R}^{+}$.

It can be checked that four conditions on $\pi$ are satisfied, which guarantee the existence of separating equilibria (see Mailath (1987)):

1. $\pi(p, \theta, \widehat{\theta})$ is twice continuously differentiable on $\mathbb{R}^{+} \times[\underline{\theta}, \bar{\theta}]^{2}$.

2. $\forall p>c_{q}(D(p, \widehat{\theta}), \theta), \pi_{\widehat{\theta}}<0$.

Indeed, $\pi_{\widehat{\theta}}=\left(p-c_{q}(D(p, \widehat{\theta}), \theta)\right) D_{\widehat{\theta}}(p, \widehat{\theta})$ and differentiating (1) with respect to $r$ and $\theta$ yields, for $\theta=\widehat{\theta}, D_{\widehat{\theta}}(p, \widehat{\theta})=(R-\widetilde{r}(p, \widehat{\theta})) v^{\prime}(t(R-$ $\widetilde{r}(p, \widehat{\theta})) / \widehat{\theta}) t(R-\widetilde{r}(p, \widehat{\theta})) / \widehat{\theta}\left(\widehat{\theta}+v^{\prime}(t(R-\widetilde{r}(p, \widehat{\theta})) / \widehat{\theta}) t^{\prime}(R-\widetilde{r}(p, \widehat{\theta}))\right)$, which is strictly positive.

3. $\pi_{p}(p, \theta, \widehat{\theta})$ is a strictly monotonic function of $\theta$.

Straightforward calculations give that $\pi_{p \theta}(p, \theta, \widehat{\theta})=-c_{q \theta}(D(p, \widehat{\theta}), \theta) D_{p}(p, \widehat{\theta})$. Hence, $\pi_{p \theta}$ is of the same sign as $c_{q \theta}$. 
4. $-\pi_{\widehat{\theta}}(p, \theta, \widehat{\theta}) / \pi_{p}(p, \theta, \widehat{\theta})$ is a strictly monotonic function of $\theta$. Differentiating $-\pi_{\widehat{\theta}}(p, \theta, \widehat{\theta}) / \pi_{p}(p, \theta, \widehat{\theta})$ with respect to $\theta$ yields

$$
\begin{aligned}
& \frac{\pi_{p \theta}(p, \theta, \widehat{\theta}) \pi_{\widehat{\theta}}(p, \theta, \widehat{\theta})-\pi_{p}(p, \theta, \widehat{\theta}) \pi_{\widehat{\theta} \theta}(p, \theta, \widehat{\theta})}{\pi_{p}(p, \theta, \widehat{\theta})^{2}} \\
= & c_{q \theta}(D(p, \widehat{\theta}), \theta) D_{\widehat{\theta}}(p, \widehat{\theta}) \frac{D(p, \widehat{\theta})}{\pi_{p}(p, \theta, \widehat{\theta})^{2}}
\end{aligned}
$$

As $D_{\widehat{\theta}}(p, \widehat{\theta})$ is strictly negative, the latter expression has the same sign as $c_{q \theta}(D(p, \widehat{\theta}), \theta)$.

From Theorem 3 in Mailath (1987), conditions 1-4 are necessary and sufficient for the existence of separating equilibria. Condition 2 indicates that the firm prefers to be perceived as clean when it prices above marginal cost. A straightforward consequence of this condition is that $\underline{\theta}$ is the worst inference consumers may draw, from the firm point of view, regardless of its true environmental performance. Condition 3 states that the profitability of changing price crucially depends on whether marginal production costs increase or decline with environmental performance. The profitability of raising price increases in true environmental cleanness when clean products are more costly to produce than dirty products. Condition 4 is the familiar single crossing property which means here that the relationship between environmental and productive efficiencies determines the monotonicity 
of $-\pi_{\widehat{\theta}}(p, \theta, \widehat{\theta}) / \pi_{p}(p, \theta, \widehat{\theta})$ with respect to $\theta$, that is, the marginal rate of substitution between price and perceived performance. In other words, for a given decrease in perceived environmental cleanness, a cleaner firm is always more willing than a dirtier one to raise price and lower sales volume, to the extent that cleaner products are more costly to produce.

Let us now turn to the derivation of separating equilibria. A general treatment can be found in Mailath (1987) and the interested reader is referred to this article for the essential details. Let $\varphi:[\underline{\theta}, \bar{\theta}] \rightarrow \mathbb{R}^{+}$denote an equilibrium strategy for the firm, hence $\varphi^{-1}(p)$ is the consumers' inference about the environmental performance of the product after observing $p$. For $\varphi$ to be an optimal strategy, it must satisfy strict incentive compatibility:

$$
\varphi(\theta)=\arg \max _{p \in \varphi([\underline{\theta}, \bar{\theta}])} \pi\left(p, \theta, \varphi^{-1}(p)\right), \forall \theta \in[\underline{\theta}, \bar{\theta}]
$$

No firm of type $\theta$ should have an incentive to charge a price other than the prescribed equilibrium price $\varphi(\theta)$.

Lemma 2 reports that there is an "absence of distortion at the bottom", namely the most polluting firm is better off charging its full information monopoly price.

Lemma 2: Under conditions 1-4, $\varphi(\underline{\theta})=p^{*}(\underline{\theta})$ in any separating equilibrium.

Proof : (see Appendix 2) 
To achieve separation, there is no need for the most polluting firm to distort its price relative to that under full information.

The firm maximization problem given in (4) can be rewritten as choosing $\widehat{\theta}$ to maximize $\Pi(\theta, \widehat{\theta}) \equiv \pi(\varphi(\widehat{\theta}), \theta, \widehat{\theta})$. The following local incentive compatibility condition must hold, for all $\theta$,

$$
\Pi_{\widehat{\theta}}(\theta, \theta)=0 .
$$

Otherwise a firm of environmental index $\theta$ could charge the same price as a firm of an index arbitrarily nearby and earn a strictly higher profit. Writing out this equation,

$$
\frac{d \varphi(\theta)}{d \theta}=\frac{-\pi_{\widehat{\theta}}(\varphi(\theta), \theta, \theta)}{\pi_{p}(\varphi(\theta), \theta, \theta)}
$$

Let us now show that all types of firm, except the most polluting one, will distort their price upward and their level of pollution downward compared to the full information case. This result is recorded in Proposition 1 and a proof can be found in Appendix 3. It turns out that $\frac{d \varphi(\theta)}{d \theta}$ and $c_{q \theta}(D(p, \widehat{\theta}), \theta)$ have the same sign.

Proposition 1: Suppose conditions 1-4 hold so that a separating price 
equilibrium with $\varphi(\theta)>c_{q}(D(\varphi(\theta), \widehat{\theta}), \theta)$ exists.

$$
\begin{aligned}
& \text { If } c_{q \theta}(D(p, \widehat{\theta}), \theta)>0 \text {, then } \frac{d \varphi(\theta)}{d \theta}>0, \varphi(\theta)>p^{*}(\theta) \\
& \text { and } t(D(\varphi(\theta), \theta))<t\left(D\left(p^{*}(\theta), \theta\right)\right), \forall \theta \in[\underline{\theta}, \bar{\theta}) \text {. }
\end{aligned}
$$

Proposition 1 states the following result. When marginal costs increase with environmental cleanness, it is possible for firms to signal their environmental friendliness with prices that rise with the product environmental performance. Consumers in turn infer higher environmental performances from higher prices. Given an equilibrium price above marginal cost, using the first order condition (6) and condition 2 yields $\pi_{p}(\varphi(\theta), \theta, \theta)<0$. As a result, firms, except the most polluting one, signal cleaner products with prices that are above the full information price. Moreover, producing to meet the lower quantity demand biases the level of pollution downward relative to that under full information.

Intuitively, when $c_{q \theta}(D(p, \widehat{\theta}), \theta)>0$, cleaner firms benefit less from pollution. Hence, they are more willing than dirtier firms to raise price and restrict output. Over-pricing is the actual means of separation because the forgone profit from raising price, hence reducing production, is less for cleaner firms. Thus, signaling a clean product induces a firm to pollute less than under full information. In the presence of asymmetric information about the environmental performance of a product, the signaling activity of imperfectly 
competitive firms is potentially a third source of market failure adding to those pointed out by Buchanan (1969), due respectively to the externality and excessive market power.

Now suppose that government labeling programs succeed in resolving consumers' uncertainty, say by providing firms with the correct incentives for fully reporting their information ${ }^{9}$. This might lead to higher levels of pollution than those resulting from the signaling behavior of firms. A single policy instrument may, at the same time, mitigate one inefficiency by fully revealing information to consumers and worsen another one by inducing firms to pollute more. Market failures cannot be separately overcome. A benevolent regulator would be faced here with three potential distortions: one is the distortion due to the externality, another one is the bias in price and production associated with the exercise of market power, and the third one is the informational distortion. Following Tinbergen (1956) and more recently Laffont (1994) and Lewis (1996), three policy instruments would then be required to achieve social efficiency: a Pigouvian tax on pollutant emissions to internalize the costs of pollution, a subsidy or a tax depending on the firm tendency to over- or under-price and a lump sum transfer to mitigate the rent of asymmetric information. Careful research is needed to address such a question in the present context.

\footnotetext{
${ }^{9}$ For instance, the regulator could allow firms to select a price-transfer contract from a carefully designed menu of such contracts in the spirit of Lewis and Sappington (1988).
} 
Finally, if cleaner products were also cheaper to produce as advocated by Porter and Van der Linde (1995), that is, $c_{q \theta}(D(p, \widehat{\theta}), \theta)<0$, then cleaner firms would find a higher price relatively less attractive than would dirtier firms. Thus, the outcome would be in the opposite direction to that stated in Proposition 1. To signal environmental performance, a cleaner firm should distort its price downward and its level of pollution upward relative to what would prevail under full information.

\section{Conclusion}

This article has investigated the signaling role of price for a firm endowed with superior information about the environmental performance of a newly introduced product. To fit one essential feature of green markets, the model assumes that consumers' willingness to pay for the product is affected by the total level of pollution associated with the product.

Separating price equilibria are shown to exist due to some essential structural properties of the model: first, the firm prefers consumers to believe its product more likely to be clean regardless of its true environmental performance, and second, the types of the firm can be ordered in such a way that a clean firm is more willing to change price than is a dirty firm. The main result is that prices are distorted relative to the full information level in order to credibly signal high environmental performance. In particular, the 
price distortion goes upward when marginal costs increase with environmental cleanness, and so the firm polluting emissions level is lower than what would prevail under full information.

Although the present result emphasizes the role of prices as possible signals of environmental performance, it cannot dismiss other decision variables that may potentially be used as signals of environmental friendliness. An obvious one is advertising ${ }^{10}$ provided that, either it has direct informational content, or advertising expenditures are observable. More generally, any observable expenditure that is likely to improve consumers' willingness to pay, such as a green technology investment for the sake of meeting ecolabeling requirements, is candidate to signal environmental performance. As the present model shares some structural properties with traditional price signaling models of quality, we can draw on recent findings of this literature to get some intuition on the relationship between price and another variable being used simultaneously to signal environmental performance. Important results reviewed in Bagwell (2005) (see also Overgaard (1991)) suggest that, if observable expenditures enhance demand, then a clean firm might signal environmental performance simultaneously with a price higher and expenditures lower than the levels that would prevail under complete information.

Hence, there is theoretical evidence that signaling distortions in price and pollution arise due to consumers' misinformation about the true envi-

\footnotetext{
${ }^{10}$ This was suggested by one referee.
} 
ronmental performance of newly introduced products. Obviously, further empirical research is needed to estimate the size of these signaling distortions and the magnitude of the efficiency losses attributable to them. In the absence of empirical work, one can hardly conclude that concern over price signaling distortions is a theoretical nicety that can be safely ignored. Surprisingly enough, signaling behaviors are seldom considered in the literature on the regulation of externalities. Nevertheless, environmental policy should be designed to deal with signaling distortions if they were of substantial magnitude. 


\section{Appendix}

\subsection{Appendix 1: Proof of lemma 1}

Subscripts denote partial derivatives. The first-order condition for profit maximization is

$$
D(p, \theta)+p D_{p}(p, \theta)-c_{q}(D(p, \theta), \theta) D_{p}(p, \theta)=0 .
$$

From (2), we get

$$
D_{p}(p, \theta)=-\left(1+v^{\prime}(t(R-r) / \theta) t^{\prime}(R-r) / \theta\right)^{-1} .
$$

Substituting for $\eta(\theta)$ in (7) and rearranging terms yields the Lerner index $\frac{p^{*}(\theta)-c_{q}\left(D\left(p^{*}(\theta), \theta\right), \theta\right)}{p^{*}(\theta)}$.

The second derivative of the profit function is

$\pi_{p p}(p, \theta)=2 D_{p}(p, \theta)+p D_{p p}(p, \theta)-c_{q q}(D(p, \theta), \theta) D_{p}^{2}(p, \theta)-c_{q}(D(p, \theta), \theta) D_{p p}(p, \theta)$.

When evaluated at the profit maximizing price, (9) becomes

$\pi_{p p}\left(p^{*}(\theta), \theta\right)=2 D_{p}\left(p^{*}(\theta), \theta\right)-\frac{D\left(p^{*}(\theta), \theta\right)}{D_{p}\left(p^{*}(\theta), \theta\right)} D_{p p}\left(p^{*}(\theta), \theta\right)-c_{q q}\left(D\left(p^{*}(\theta), \theta\right), \theta\right) D_{p}^{2}\left(p^{*}(\theta), \theta\right)$. 
From (8),

$$
D_{p p}(p, \theta)=-\frac{v^{\prime \prime} t^{\prime 2}+v^{\prime} t^{\prime \prime}}{\left(\theta+v^{\prime} t^{\prime}\right)^{2}}<0 .
$$

Thus, $\pi_{p p}\left(p^{*}(\theta), \theta\right)<0$, which guarantees that $p^{*}(\theta)$ is a local maxima.

\subsection{Appendix 2: Proof of lemma 2}

Had the type $\underline{\theta}$ set an equilibrium price $\varphi(\underline{\theta}) \neq p^{*}(\underline{\theta})$, then the deviation to $p^{*}(\underline{\theta})$ would be profitable, regardless of whether $p^{*}(\underline{\theta})$ is on or off the equilibrium path: if $p^{*}(\underline{\theta})$ is on the equilibrium path, then $p^{*}(\underline{\theta})=\varphi(\theta)$ for some $\theta \in[\underline{\theta}, \bar{\theta})$ and consumers draw inference $\theta$ from observing $\varphi(\theta)$, $\pi(\varphi(\theta), \underline{\theta}, \theta)>\pi\left(p^{*}(\underline{\theta}), \underline{\theta}, \underline{\theta}\right)$ since $\underline{\theta}$ is the worst belief from condition 2, and $\pi\left(p^{*}(\underline{\theta}), \underline{\theta}, \underline{\theta}\right) \geq \pi(\varphi(\underline{\theta}), \underline{\theta}, \underline{\theta})$ by definition of $p^{*}(\underline{\theta})$; if $p^{*}(\underline{\theta})$ is off the equilibrium path, then consumers' beliefs are arbitrary after observing $p^{*}(\underline{\theta})$, say $\theta$, and $\pi\left(p^{*}(\underline{\theta}), \underline{\theta}, \theta\right)>\pi\left(p^{*}(\underline{\theta}), \underline{\theta}, \underline{\theta}\right) \geq \pi(\varphi(\underline{\theta}), \underline{\theta}, \underline{\theta})$.

\subsection{Appendix 3: Proof of proposition 1}

Consider equilibrium prices set above marginal cost so that condition 2 will be met in equilibrium. Differentiating (5) with respect to $\theta$ yields $\Pi_{\widehat{\theta}}(\theta, \theta)=$ $-\Pi_{\widehat{\theta} \widehat{\theta}}(\theta, \theta)$. Thus, the local second order condition for the maximization problem is equivalent to $\Pi_{\theta \widehat{\theta}}(\theta, \theta) \geq 0$, that is,

$$
\pi_{p \theta}(\varphi(\theta), \theta, \theta) \frac{d \varphi(\theta)}{d \theta}+\pi_{\widehat{\theta} \theta}(\varphi(\theta), \theta, \theta) \geq 0 .
$$


Using (6) gives

$$
\frac{d \varphi(\theta)}{d \theta}\left[\pi_{p \theta}(\varphi(\theta), \theta, \theta)-\frac{\pi_{p}(\varphi(\theta), \theta, \theta)}{\pi_{\widehat{\theta}}(\varphi(\theta), \theta, \theta)} \pi_{\widehat{\theta} \theta}(\varphi(\theta), \theta, \theta)\right] \geq 0
$$

Therefore, the sign of $\frac{d \varphi(\theta)}{d \theta}$ is the same as the sign of the second factor in the left-hand side of (13), which depends on the monotonicity of $-\pi_{\widehat{\theta}}(p, \theta, \widehat{\theta}) / \pi_{p}(p, \theta, \widehat{\theta})$ with respect to $\theta$. From condition 4 , the second factor in the left-hand side of $(13)$ and $c_{q \theta}(D(p, \widehat{\theta}), \theta)$ have the same sign. 


\section{References}

[1] ANDREONI, J. (1995), "Warm-Glow Versus Cold-Prickle: The Effect of Positive and Negative Framing on Cooperation in Experiments", Quarterly Journal of Economics 60, 1-21.

[2] ARORA, S. and GANGOPADHYAY S. (2003), "Toward a Theoretical Model of Voluntary Overcompliance", Journal of Economic Behavior and Organization 28, 289-309.

[3] BANSAL, S. and GANGOPADHYAY S. (2003), "Tax/Subsidy Policies in the Presence of Environmentally Aware Consumers", Journal of Environmental Economics and Management 45, 333-355.

[4] BAGWELL, K. (2005), "The Economic Analysis of Advertising" forthcoming in M. Armstrong and R. Porter (eds), Handbook of Industrial Organization, Vol. 3, Elsevier/North-Holland.

[5] BAGWELL, K. and M. H. RIORDAN (1991), "High and Declining Prices Signal Product Quality", American Economic Review 81, 224239.

[6] BARNETT, A. (1980), "The Pigouvian Tax Rule under Monopoly", American Economic Review 70, 1037-1041.

[7] BAUMOL, J. and W. E. OATES (1975), The Theory of Environmental Policy, Second Edition, Cambridge: Cambridge University Press. 
[8] BOULDING, W. and A. KIRMANI (1993), "A Consumer-Side Experimental Examination of Signaling Theory: Do Consumers Perceive Warranties as Signals of Quality?", Journal of Consumer Research 20, 111123.

[9] BOYER, M., MAHENC P. and M. MOREAUX (2004), "Environmental Protection, Consumers Awareness, Product Characteristics and Market Power" forthcoming in M. Boyer, Y. Hiriart and D. Martimort (eds), Frontiers in the Economics of Environmental Regulation and Liability, Ashgate Pub.

[10] BUCHANAN, J. M. (1969), "External Diseconomies, Corrective Taxes and Market Structures", American Economic Review 59, 174-177.

[11] CAIRNCROSS, F.(1992), "Costing the Earth", Harvard University Press, Cambridge, MA.

[12] CASON, T. N. and L. GANGADHARAN. (2002), "Environmental Labelling and Incomplete Consumer Information in Laboratory Experiments", Journal of Environmental Economics and Management 43, 113134.

[13] CHURCH J. (1994), "A Market Solution to Green Marketing: Some Lessons from the Economics of Information", Minnesota Law Review $79,245-324$. 
[14] CREMER, H. and J.-F. THISSE (1999), "On the Taxation of Polluting Products in a Differentiated Industry", European Economic Review 43, $575-594$.

[15] DELTAS G., M. KHANNA and D. T. RAMIREZ (2004), "Markets with Environmentally Conscious Consumers", Working Paper, University of Illinois.

[16] INNES R. and J. J. BIAL. (2003), "Inducing Innovation in the Environmental Technology of Oligopolistic Firms", The Journal of Industrial Economics 3, 265-287.

[17] IYER, E. and B. BANERJEE (1993), "Anatomy of Green Advertsing" in Advances in Consumer Research, L. McAlister and M. Rothschild, Eds, Vol 20, pp. 292-298, Association for Consumer Research, Provo, UT.

[18] KARL H. and C. ORWAT (1999), "Economic Aspects of Environmental Labelling" in H. Folmer and T. Tietenberg (eds), Yearbook of Environmental and Resource Economics 1999/2000, Elgar, Cheltenham, UK, $107-170$.

[19] KOLSTAD, C. D. (2000), Environmental Economics, Oxford University Press. 
[20] LAFFONT, J.- J. (1994), "Regulation of Pollution with Asymmetric Information" in C. Dosi and T. Tomasi (eds), Nonpoint Source Pollution Regulation: Issues and Analysis, Dordrecht: Kluwer Academic Publishers, 39-66.

[21] LEWIS, T., R. (1996), "Protecting the Environment when Costs and benefits are privately Known", Rand Journal of Economics 27, $\mathrm{n}^{\circ} 4$, 819-847.

[22] LEWIS, T. R. and D. SAPPINGTON (1988), "Regulating a Monopolist with Unknown Demand", American Economic Review 78, 986-998.

[23] MAILATH G. (1987), "Incentive Compatibility in Signaling Games with a Continuum of Types", Econometrica 55, 1349-1365.

[24] MEADE J. E. (1952), "External Economies and Diseconomies in a Competitive Situation", Economic Journal 62, 54-67.

[25] MILGROM, P. and J. ROBERTS (1986), "Price and Advertising Signals of Product Quality", Journal of Political Economy 94, 796-821.

[26] NELSON, P. (1970), "Information and Consumer Behaviour", Journal of Political Economy 78, 311-329.

[27] NIMON, W. and J. BEGHIN (1999), "Are Eco-labels Valuable? Evidence from the Apparel Industry", American Journal of Agricultural Economics 81, 801-811. 
[28] OVERGAARD, P. B. (1991), Product Quality Uncertainty: Strategic Information Transmission in Product Markets with Adverse Selection and Adverse Incentives, CIACO, Louvain-la-Neuve: Belgium.

[29] PALMER, K., W. E. OATES and P. R. PORTNEY (1995), "Tightening Environmental Standards: The Benefit Cost or the No-Cost Paradigm?", Journal of Economic Perspectives Vol. 9, № 4, 119-132.

[30] PORTER, M. E. and VAN der LINDE, C. (1995), "Toward a New Conception of the Environment-Competitiveness", Journal of Economic Perspectives Vol. 9, № 4, 97-118.

[31] SCHMALENSEE, R. (1978), "A Model of Advertising and Product Quality", Journal of Political Economy, Vol. 86, pp. 485-503.

[32] SPENCE, A. M. (1973), "Job Market Signaling", Quarterly Journal of Economics 85, 355-379.

[33] TIROLE, J. (1988), The theory of Industrial Organization. Cambridge, Mass.: MIT Press.

[34] TINBERGEN, J. (1956), Economic Policy: Principles and Design. Amsterdam: North-Holland. 